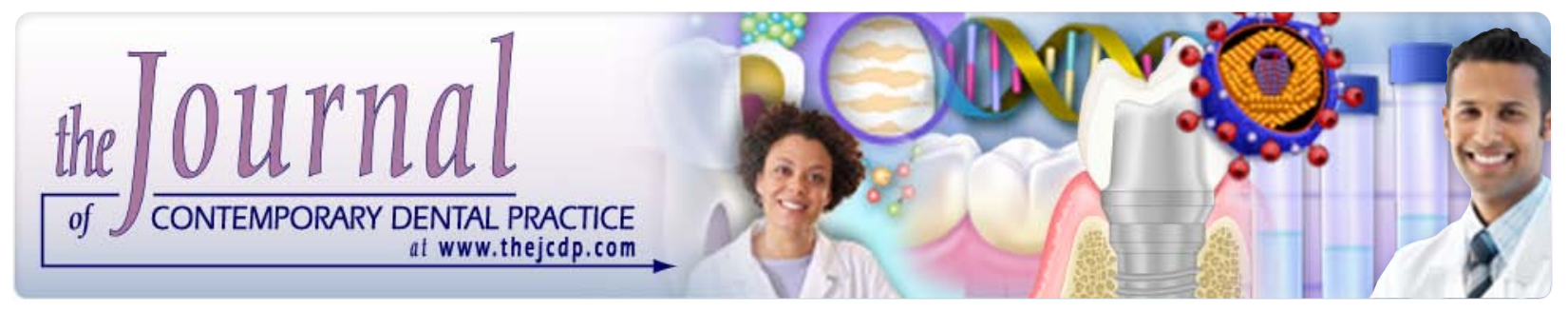

\title{
A Case of Extensive Maxillary Benign Cementoblastoma
}

Rivadávio Fernandes Batista de Amorim, DDS, MSc, PhD; Éricka Janine Dantas Silveira, DDS, MSc, PhD; Mariana Nóbrega França, DDS; Maria do Carmo Machado Guimarães, DDS, MSc, PhD; Normeu Lima Júnior, DDS, MSc.; Daniel Rey de Carvalho, DDS, MSc, PhD

\section{Abstract}

Aim: The aim of the present paper is to report a case of benign cementoblastoma (BC) involving multiple maxillary teeth and discuss the importance of its diagnosis in clinical oral practice.

Background: $B C$ is a rare, benign odontogenic neoplasm of ectomesenchymal origin. This neoplasm has characteristic radiologic and microscopic features, and it is intimately associated with the roots of teeth.

Case Report: The intra-oral examination in a 21-year-old white man revealed a palatine growth in the premolar-molar region. Dental panoramic and periapical radiographies showed a mixed radiodense/radiolucent lesion closely associated with the roots of three maxillary teeth. A biopsy was undertaken and confirmed the clinical hypothesis.

Summary: In most cases, initial BC is asymptomatic and early diagnosis can be performed by routine radiographic examination. $\mathrm{BC}$ was considered as an indolent lesion for several years. Nevertheless, recent studies have demonstrated that some BCs may exhibit aggressive biological behavior and can affect several teeth.

Clinical Significance: Because a benign cementoblastoma represents an odontogenic lesion, general practicing professionals must be able to identify the main features of this tumor. This case corroborates some papers that have

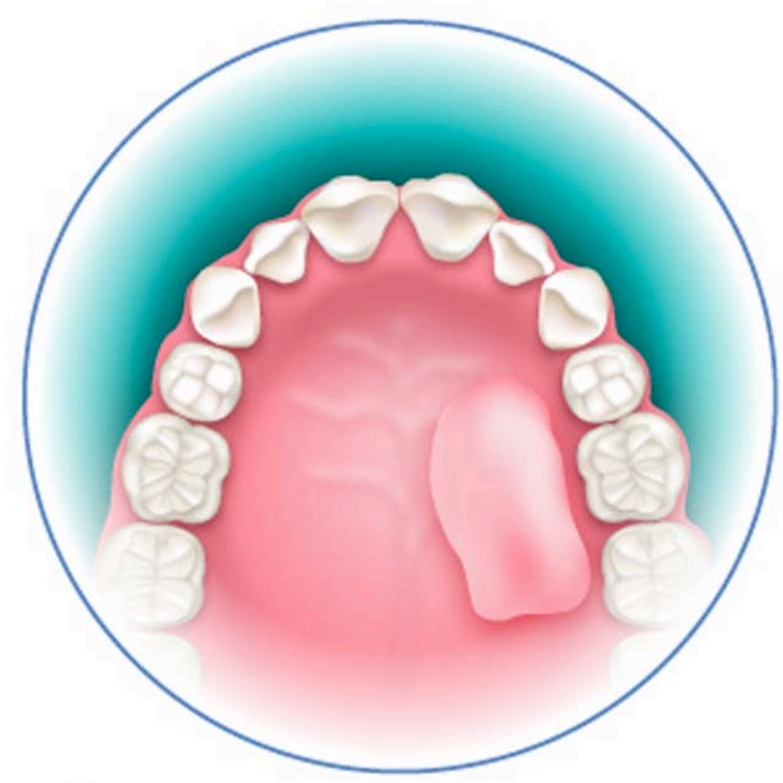

demonstrated a possible aggressive behavior of BC. Therefore, a brief update concerning the clinical and radiographic features of this unique tumor is also provided.

Keywords: Benign cementoblastoma, odontogenic tumor, benign tumor, cementoblasts, maxillary sinus.

Citation: Amorim RFB, Silveira EJD, França MN, Guimarães MCM, Lima Júnior N, Carvalho DR. A Case of Extensive Maxillary Benign Cementoblastoma. J Contemp Dent Pract [Internet]. 2010 May; 11(3):056-062. Available from: http://www.thejcdp.com/journal/view/ volume11-issue3-amorim 


\section{Introduction}

The benign cementoblastoma $(\mathrm{BC})$ is a relatively rare ectomesenchymal odontogenic neoplasm, representing about 1 to 6.2 percent of all odontogenic tumors. It can be defined as a benign neoplasm of functional cementoblasts that produce a mass of cementum in association with a tooth root. ${ }^{1-3}$ Generally, it shows a slight prevalence for males (1.2:1) and young people, and is considered the only true neoplasm of cementum origin. $\mathrm{BC}$ was first described by Dewey $^{4}$ in 1927, and it was characterized as being attached to the root of a permanent tooth, most often the first molar and second premolar in the mandible. Most common symptoms include pain and swelling. However, initial lesions are often asymptomatic. Radiographically, a benign cementoblastoma appears as a radiopaque mass with a thin radiolucent rim attached to the roots of a tooth. Even though final diagnosis is reached by histopathologic examination, it is important to mention that associated clinical and radiographic findings are highly suggestive..$^{5.6}$ The recommended treatment is complete enucleation of the tumor and extraction of the involved tooth/teeth. BC was considered as an indolent lesion for several years inasmuch as available data were scarce. Nevertheless, studies have demonstrated that some BCs may exhibit aggressive biological behavior and can affect more than one tooth. ${ }^{7-11}$ The aim of this report is to present an unusual case of $B C$ involving multiple maxillary teeth in a 21 -year-old Caucasian male and discuss the importance of its diagnosis in clinical practice.

\section{Case Report}

A 21-year-old Caucasian male who had been suffering from oral discomfort was admitted to the Oral Pathology Department of Catholic University of Brasília for the diagnosis and management of a maxillary lesion. According to the patient's report, the lesion was first noticed two years before our evaluation. Since then, it had increased in size, and the patient underwent a previous "osteoplasty" procedure because of buccal expansion and facial asymmetry.

Physical examination detected the presence of left-sided tumefaction displaying discrete facial asymmetry. The intraoral examination revealed a palatine growth in the premolar-molar region (Figure 1). The overlying mucosa showed surface ulceration. Dental panoramic and periapical radiographies were taken and showed a mixed radiopaque/radiolucent lesion closely associated with the roots of the maxillary left first and second premolar and first molar (Figures 2 and 3 ). Thus, these clinical and radiological findings were highly suggestive of BC. An incisional biopsy specimen was undertaken and confirmed the clinical hypothesis.

Complete extirpation of the neoplasm was performed by enucleation under general anesthesia (via nasotracheal intubation) at the Hospital of Catholic University of Brasília. Macroscopically, the lesion showed a calcified mass measuring $3.5 \mathrm{~cm} \times 2.5 \mathrm{~cm} \times 2.1 \mathrm{~cm}$ (Figure 4). It was necessary to extract four teeth compromised by the lesion (maxillary premolars and molars). At the time of surgery, involvement of the maxillary sinus floor was visualized (Figure 5). Thus, curettage of the left mucosa of the sinus was performed. The tumor was well demarcated from the surrounding bone, and it could be readily removed. The adjacent remaining teeth showed no signs of resorption.

Histological investigation revealed an odontogenic lesion composed mainly of multiple cementlike trabeculae containing irregular lacunae. Reversal lines could be detected in some areas of the specimen. In others, densely calcified areas were found and cementoblasts appeared entrapped by the calcified matrix. Cementoblastic activity also was observed and represented a marked finding in this case (Figures 6 and 7).

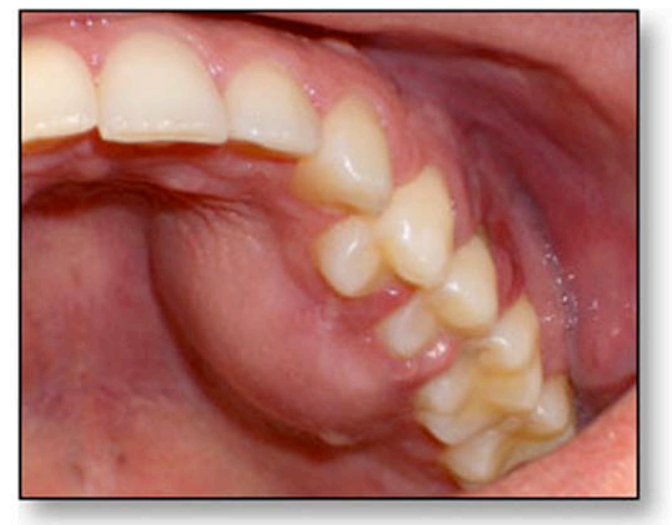

Figure 1. Intraoral view demonstrating an extensive tumefaction in left maxilla. 


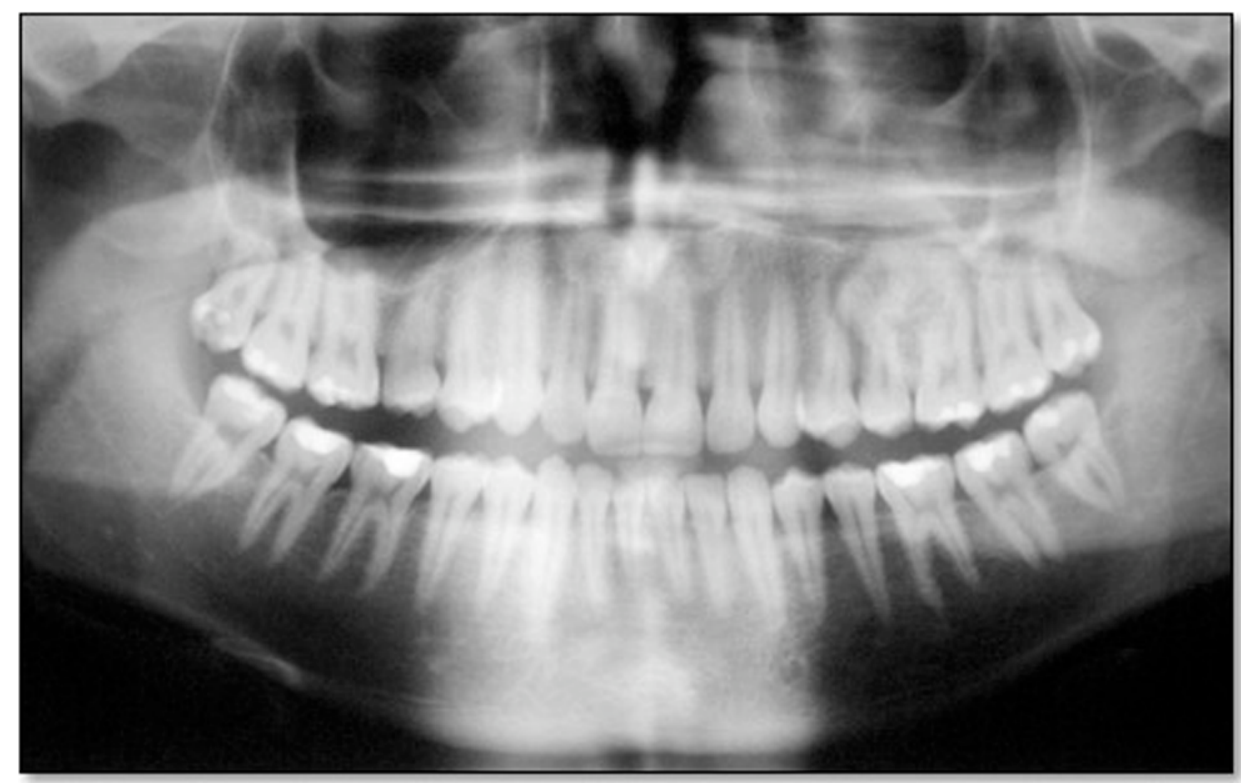

Figure 2. Dental panoramic radiograph obtained during the initial presentation showed a mixed radiolucent/radiodense lesion.

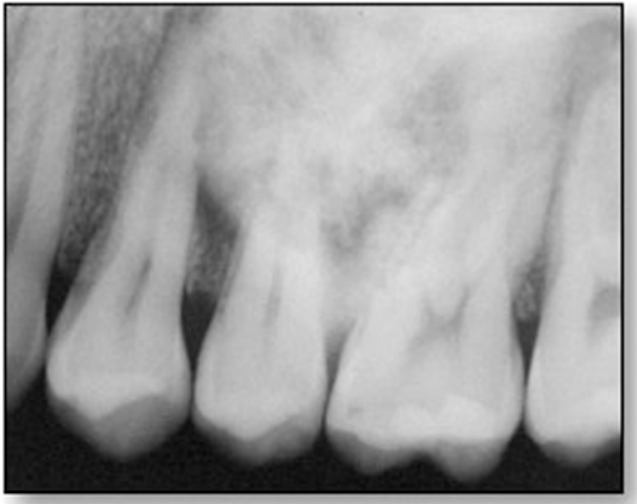

Figure 3. Periapical radiograph showing close association with the roots of adjacent teeth.

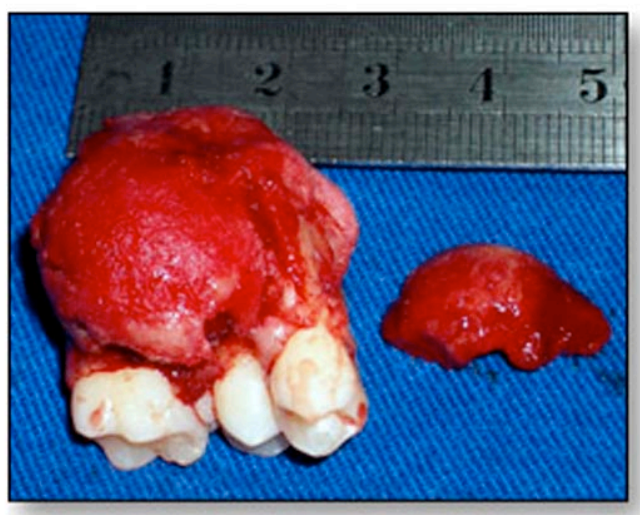

Figure 4. Surgical specimen of the tumor and associated teeth. The second molar also was extracted (not in view).

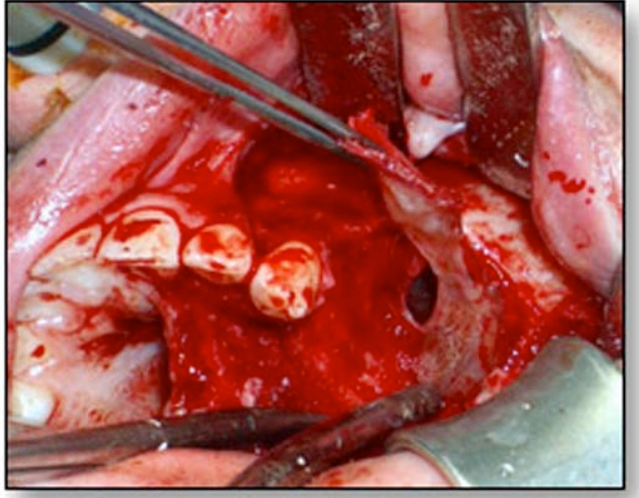

Figure 5. Transoperative view showing sinus involvement.

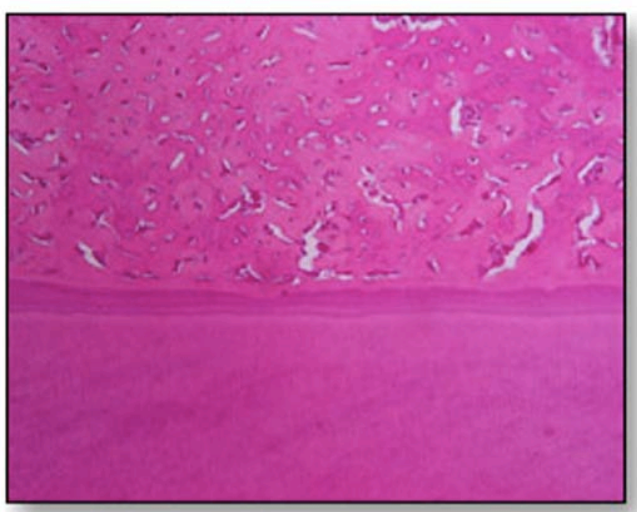

Figure 6. Histological section showed cementum tissue with irregular lacunae and entrapped cells attached to the tooth root (HE, 100x). 


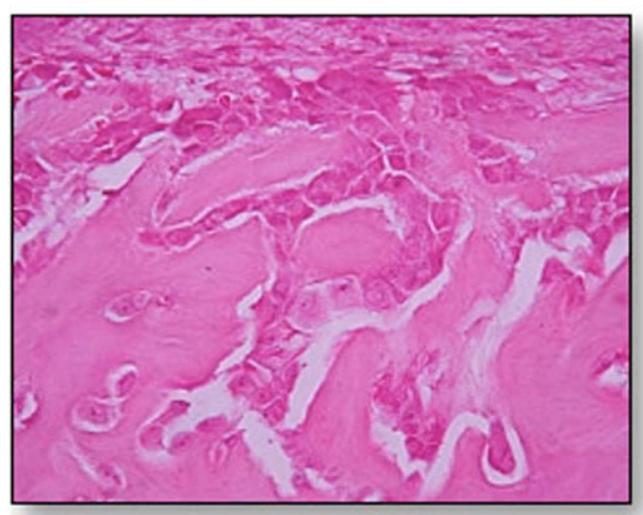

Figure 7. Higher magnification demonstrating intense cementoblastic activity (HE, 400x).

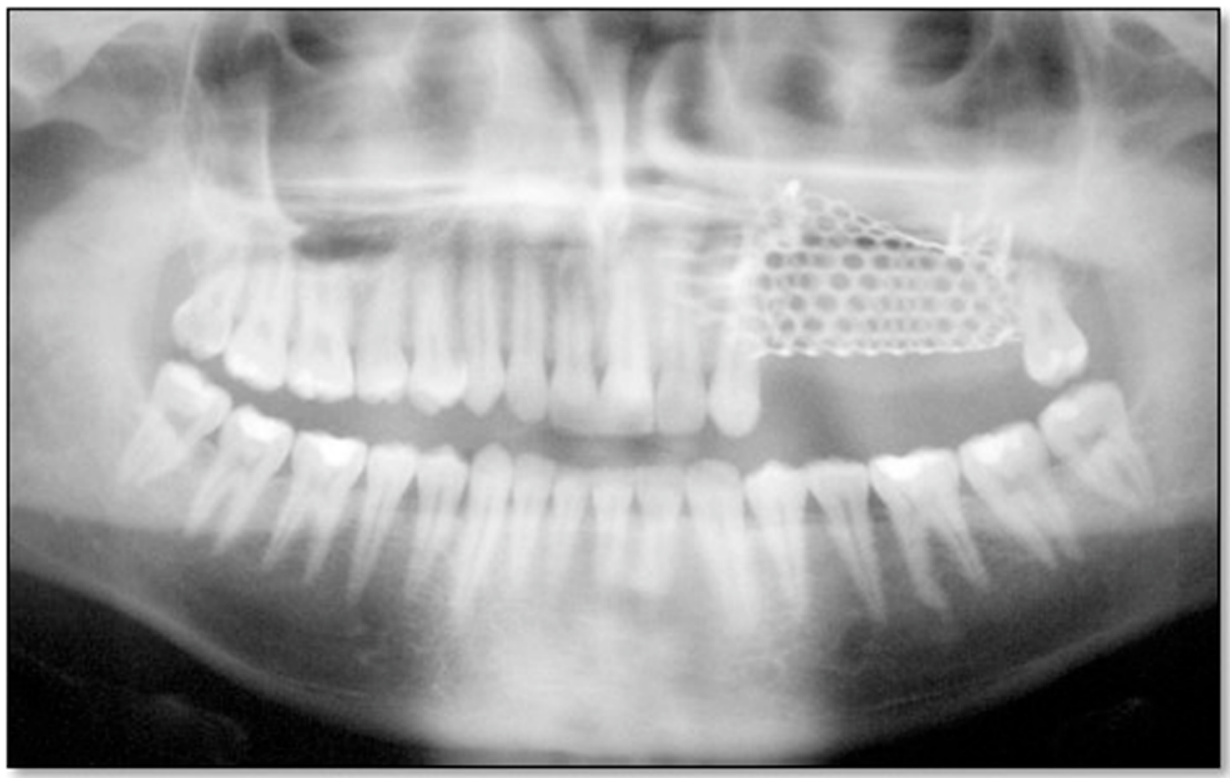

Figure 8. Postoperative panoramic radiograph of the patient showing four teeth had been removed.

A postoperative radiograph taken 21 days after surgical removal showed signs of normal repair. A complete oral rehabilitation was proposed; however, the patient refused the recommended treatment (Figure 8). A control panoramic radiographic was taken one year after the surgery, confirming normal osseous repair.

\section{Discussion}

Of all swellings of the oral cavity, only 9 percent are odontogenic tumors, and within this group, a benign cementoblastoma is one of the rarest lesions. A BC is recognized by the World Health Organization's classification system as one of four types of cementum-producing disorders (the others being periapical cemental dysplasia, cementifying fibroma, and gigantiform familial cementoma). ${ }^{12}$ Nonetheless, a new classification was proposed, and BC is now included in the group of "mesenchyme and/or odontogenic ectomesenchyme, with or without odontogenic epithelium" odontogenic tumors. ${ }^{13}$ Some investigations have stated that $\mathrm{BC}$ represents less than 1 percent of all odontogenic tumors. Thus, studies and reports regarding its etiology, evolution, clinical behavior, and treatment are still scarce. . $3 ., 5,14,15$

$\mathrm{BC}$ is a neoplasm that is characterized by intense deposition of cementum surrounding the apical region of a tooth root. This tissue has special relevance in oral practice, and it has singular features. It shows close relation to bone in regard 
to the inorganic elements. However, cementum does not demonstrate the lamellar organization found in bone, is avascular in most species studied, is noninnervated, does not contain bone marrow, and does not undergo the physiological remodeling seen in bone. Also, it is not known whether cementoblasts and osteoblasts have a common precursor in the periodontal ligament, or whether distinct precursors even exist. ${ }^{9.16}$ The general appearance of BC may sometimes resemble other lesions, especially osteoma or osteoblastoma. It is stated that the most important radiographic feature for differential diagnosis of a benign cementoblastoma is attachment to tooth roots. We believe, however, that the involvement of the roots seen on radiographic examination should not rule out the diagnosis of this lesion. The best way to establish final diagnosis is the detection of the direct connection with the radicular surface verified by microscopic analysis. Thus, the cementoblastoma is continuous with the cemental layer of the apical third of the tooth root and remains separated from bone by a continuation of the periodontal ligament. ${ }^{5,7,8}$

Generally, symptoms are absent or tend to be minor in early BCs. As the lesion develops, swelling accompanied by pain is the most common finding at clinical evaluation.

Approximately, 65 percent of the cases are clinically symptomatic before diagnosis. $\mathrm{BC}$ is commonly found during the second and third decades of life. A clinicopathologic study of 44 cases performed by Brannon et al. ${ }^{11}$ found a mean age of 20.7 years old for BC. Several other studies have corroborated this finding. $\frac{7.8,10,17}{}$ Our case was in accordance with the literature regarding this feature.

Most cases of $\mathrm{BC}$ are described in the premolarmolar region, more commonly in the mandible than in the maxilla. ${ }^{15,18}$ An important feature of the present case is that the tumor occurred in the left maxillary region, representing an unusual anatomical location for this lesion. Ohki et al..$^{\underline{7}}$ reviewed 12 reports of $B C$ involving multiple teeth between 1961 and 2003. Interestingly, most cases of extensive BCs were found in the maxilla. To date, the literature has not been able to explain the aggressive nature of $\mathrm{BC}$ located at this anatomical site.

Histopathologically, the lesion is composed predominantly of sheets or trabeculae of cementum-like calcified tissue. Other findings are represented by the presence of reversal lines and cellular areas. The periphery of the mass or the more-active growth areas are often unmineralized. $\frac{5,11}{1 n}$ the present case, active cementoblasts were seen in many microscopic areas, which suggests the potential for more aggressive growth.

This lesion has been considered for a long period as an innocuous neoplasm. Nonetheless, it must be pointed out that most clinical cases and epidemiological series have a short followup period. As a consequence, it is stated that $\mathrm{BC}$ can be conservatively treated with virtually few chances for recurrence. In contrast, recent papers give special emphasis to the clinical behavior of $\mathrm{BC}$, and state that some tumors may cause severe destruction. ${ }^{7.11}$ In theory, $\mathrm{BCs}$ have unlimited potential growth and endodontic therapy will not eliminate or arrest them. An appropriate treatment must be provided to remove the entire neoplasm. Extraction of the involved tooth or teeth along with removal of the lesion is highly recommended to prevent recurrences. Moreover, additional curettage and/or peripheral ostectomy must be considered. ${ }^{8}$ Curiously, some authors have proposed that it may be possible to remove $\mathrm{BC}$ affecting molars without extracting the involved teeth. Endodontic therapy, retreatment of an existing root canal filling, and root amputation have been recommended. ${ }^{19}$ In our opinion, a conservative approach for managing $\mathrm{BC}$ must be taken into consideration, if the neoplastic process is diagnosed early and the patient is highly cooperative.

In the present study, the lesion size was bigger than that described by most authors. ${ }^{5.9 .10}$ After total enucleation the lesion measured approximately $3.5 \times 2.5 \mathrm{~cm}$. It must be remembered that the patient was subjected to a previous osteoplasty in which the buccal aspect of the lesion already had been removed. Had this procedure not been performed, the lesion likely would have grown to an even greater diameter.

It is not well established which biological factors are closely related to BC growth, especially in aggressive cases. However, an interesting study, published by Arzate et al., ${ }^{20}$ investigated the molecular mechanisms related to the cementogenesis process. The authors concluded that a cementoblastoma-conditioned 
medium-derived protein $(\mathrm{CP})$ could be useful as a cementum biological marker because it indentified cementoblast progenitor cells and demonstrated the presence of cementum. Thus, immunohistochemical studies (antibodies against $\mathrm{CP}$ ) with intense staining may be associated with aggressive BCs.

\section{Summary}

In most cases, BC is asymptomatic and an early diagnosis can be obtained on routine radiographic examination. In general, clinicians elect to use conservative therapeutics for treatment, including single surgical removal of both the tooth and tumor. However, it must be mentioned that a careful evaluation is necessary in order to identify patients with an aggressive lesion, as in the present case.

\section{Clinical Significance}

In this report, we present a rare case of a benign cementoblastoma that is interesting to consider due to its localization and involvement of multiple teeth. Moreover, it is important to state that patients with this lesion should be routinely evaluated by a specialist due to the unpredictable clinical course and outcome found in some BCs.

\section{References}

1. Pippi R. Benign odontogenic tumours: Clinical, epidemiological and therapeutic aspects of a sixteen years sample. Minerva Stomatol. 2006; 55(9):503-13.

2. Sriram G, Shetty RP. Odontogenic tumors: a study of 250 cases in an Indian teaching hospital. Oral Surg Oral Med Oral Pathol Oral Radiol Endod. 2008; 105(6):e14-21.

3. Ochsenius G, Ortega A, Godoy L, Peñafiel C, Escobar E. Odontogenic tumors in Chile: a study of 362 cases. J Oral Pathol Med. 2002; 31(7):415-20.

4. Dewey KW. Osteoma of a molar. Dent Cosmos. 1927; 69:1143-9.

5. Zaitoun H, Kujan O, Sloan P. An unusual recurrent cementoblastoma associated with a developing lower second molar tooth: a case report. J Oral Maxillofac Surg. 2007; 65(10):2080-2.
6. Infante-Cossio P, Hernandez-Guisado JM, Acosta-Feria M, Carranza-Carranza A. Cementoblastoma involving the maxillary sinus. Br J Oral Maxillofac Surg. 2008; 46(3):234-6.

7. Ohki K, Kumamoto H, Nitta Y, Nagasaka $\mathrm{H}$, Kawamura H, Ooya K. Benign cementoblastoma involving multiple maxillary teeth: report of a case with a review of the literature. Oral Surg Oral Med Oral Pathol Oral Radiol Endod. 2004; 97(1):53-8.

8. Sumer M, Gunduz K, Sumer AP, Gunhan O. Benign cementoblastoma: a case report. Med Oral Patol Oral Cir Bucal. 2006; 11(6):483-5.

9. Neves FS, Falcão AF, Dos Santos JN, Dultra FK, Rebello IM, Campos PS. Benign cementoblastoma: case report and review of the literature. Minerva Stomatol. 2009; 58 (1-2):55-9.

10. Hachimi H, Oudidi A, Benmansour N, Kadaoui H, Zaki Z, Ridal M, El Alami MN. [Benign cementoblastoma. Apropos of a case and review of the literature]. Odontostomatol Trop. 2005; 28(112):24-6.

11. Brannon RB, Fowler CB, Carpenter WM, Corio RL. Cementoblastoma: an innocuous neoplasm? A clinicopathologic study of 44 cases and review of the literature with special emphasis on recurrence. Oral Surg Oral Med Oral Pathol Oral Radiol Endod. 2002; 93(3):311-20.

12. Kramer IRH, Pindborg JJ, Shear M. Histological typing of odontogenic tumours. 2nd ed. Berlin: Springer-Verlag; 1992. p.7, 23-4.

13. Barnes L, Eveson JW, Reichart P, Sidransky D., editors. World Health Organization classification of tumours: pathology and genetics of head and neck tumours. Lyon: IARC Press; 2005. p. 283-328.

14. Cundiff EJ 2nd. Developing cementoblastoma: case report and update of differential diagnosis. Quintessence Int. 2000; 31(3): 191-5.

15. Schafer TE, Singh B, Myers DR. Cementoblastoma associated with a primary tooth: a rare pediatric lesion. Pediatr Dent. 2001; 23(4):351-3.

16. Bosshardt DD. Are cementoblasts a subpopulation of osteoblasts or a unique phenotype? J Dent Res. 2005; 84(5):390-406.

17. Vieira AP, Meneses JM Jr, Maia RL. Cementoblastoma related to a primary tooth: a case report. J Oral Pathol Med. 2007; 36(2):117-9. 
18. Lemberg K, Hagström J, Rihtniemi J, Soikkonen K. Benign cementoblastoma in a primary lower molar, a rarity Dentomaxillofac Radiol. 2007; 36(6):364-6.

19. Biggs JT, Benenati FW. Surgically treating a benign cementoblastoma while retaining the involved tooth. J Am Dent Assoc. 1995; 126(9):1288-90.

20. Arzate H, Jiménez-García LF, ÁlvarezPérez MA, Landa A, Bar-Kana I, Pitaru S. Immunolocalization of a human cementoblastoma-conditioned mediumderived protein. J Dent Res. 2002; 81(8): 541-6.

\section{About the Authors}

Rivadávio Fernandes Batista de Amorim, DDS, MSc, PhD (Corresponding Author)

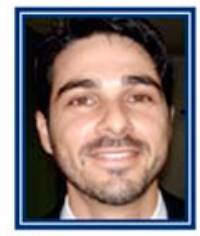

Dr. Amorim is professor of pathology in the School of Medicine, University of Brasília (UnB-DF), Brasília, DF, Brazil. His research includes odontogenic cysts and tumors, oral cancer and immunological oral diseases.

e-mail: rivadavioamorim@hotmail.com

Éricka Janine Dantas Silveira, DDS, MSc, PhD

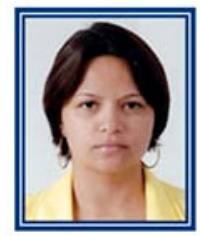

Dr. Silveira is an adjunct professor of oral pathology and immunology in the Dentistry Departament, Federal University of Rio Grande do Norte (UFRN), Natal-RN, Brazil. Her research interests include oral and maxillofacial lesions and oral cancer using immunohistochemistry method.

e-mail: ericka_janine@yahoo.com.br

\section{Mariana Nóbrega França, DDS}

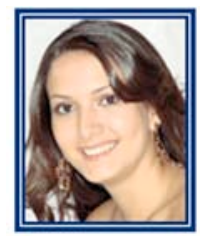

Dr. França is a recent graduate of the School of Dentistry, Catholic University of Brasilia (UCB), Brasilia-DF, Brazil.
Maria do Carmo Machado Guimarães, DDS, MSc, PhD

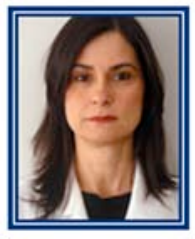

Dr. Guimarães is an adjunct professor of periodontics in the Periodontics Division, University of Brasilia (UnB-DF), Brasília, DF, Brazil. Her research interests include inflammatory mediators in periodontal disease, the interrelationship between diabetes mellitus and periodontal disease, and disturbance in the oral cavity.

e-mail: mmgcarmo@gmail.com

Normeu Lima Júnior, DDS, MSc.

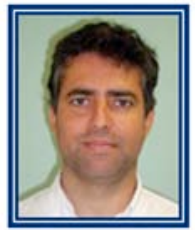

Dr. Lima Júnior is professor of oral surgery in the School of Dentistry, Catholic University of Brasília (UCB), Brasília-DF, Brazil. His research interests include treatment of oral cysts and tumors and dental implants.

e-mail:normeu@ucb.br

Daniel Rey de Carvalho, DDS, MSc, PhD

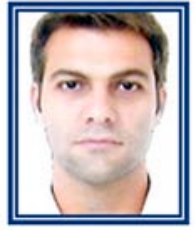

Dr. Carvalho is the director of the Graduate School of Dentistry, Catholic University of Brasília (UCB), Brasília, DF, Brazil. His research includes molecular biology and nanotechnology applied in dentistry.

e-mail: rey@ucb.br 